\title{
DESAFIOS E POSSIBILIDADES DE LEITURA LITERÁRIA NA EDUCAÇÃO DE JOVENS E ADULTOS
}

\section{CHALLENGES AND POSSIBILITIES IN READING LITERATURE IN THE YOUTH AND ADULT EDUCATION}

\author{
Sheila Oliveira Lima ${ }^{65}$ \\ Rosangela Maria de Almeida Netzel ${ }^{66}$
}

\begin{abstract}
RESUMO: Com o objetivo de investigar possibilidades de leitura literária na fase inicial da Educação de Jovens e Adultos (EJA), têm sido realizadas, semanalmente, práticas de leitura, por uma pesquisadora-mediadora na biblioteca escolar de uma escola pública no estado do Paraná. Os materiais adotados para a realização das atividades de leitura compõem-se de livros enviados pelo Ministério da Educação às escolas que abrigam a EJA. Destacam-se, no acervo enviado, obras de qualidade editorial e literária, com as quais é possível realizar mediações que focam na motivação para a leitura. O referencial teórico eleito para embasar tal estudo se constitui de teorias que vinculam aspectos da subjetividade à atividade de leitura, centradas em discussões trazidas por autores como Barthes (2004), Petit (2009), Pastorello (2015) e Colomer (2007). Para tanto, empregase como encaminhamento metodológico a pesquisa bibliográfica, de cunho qualitativo, seguida de relato das experiências de leitura já realizadas com a EJA, em um movimento de reflexão sobre futuras práticas para a superação de desafios quanto ao ensino de leitura na EJA Fase I.
\end{abstract}

PALAVRAS-CHAVE: Ensino. Leitura. Subjetividade. EJA

ABSTRACT: Aiming to investigate the possibilities of reading literature in the initial phase of Youth and Adult Education (EJA), weekly researcher-mediated readings have been taking place in the library of a public school of the State of Paraná. The learning and teaching materials for the readings are those adopted and sent by Brazilian Federal Ministry of Education to the EJA-harboring schools. Among those instructional materials, oeuvres of high editorial and literary quality stand out, with such oeuvres the researcher can mediate reading sessions focused on the students'motivation to read. The theoretical framework selected to base this research is contituited by theories which link aspects of subjetivity to reading, especially those theories which pay particular attention to the discussions raised by Barthes (2004), Petit (2009), Pastorello (2015) and Colomer (2007). The researcher, first, carries out a quallity-blased bibliographical research among the aforesaid learning and teaching materials, and then, relates the reading experiences performed in EJA, in order to reflect on future pratices for overcoming the presente challenges in teaching/learning how to read in phase I EJA.

KEYWORDS: Teaching. Reading. Subjetivity. EJA.

\section{Introdução}

A Educação de Jovens e Adultos (EJA), Fase I (correspondente aos anos iniciais do Ensino Fundamental), tem recebido, nos últimos anos, pouca atenção no que se refere à produção e encaminhamento de materiais de ensino às escolas. A última escolha de livros didáticos realizada pelo Programa Nacional do Livro Didático (PNLD) ocorreu no ano de 2014, obrigando os professores a reutilizar uma mesma obra ao longo dos três anos que perfazem o ciclo em questão, isto é, repetindo atividades, leituras e abordagens, o que se torna um fator de desmotivação num segmento já tão fragilizado.

A divulgação de materiais para a EJA é pequena se comparada àquela voltada para os Anos Iniciais do Ensino Fundamental direcionada às crianças, por exemplo, o que leva muitos

${ }^{65}$ Doutora em Educação, pela Faculdade de Educação da Universidade de São Paulo (USP). Docente no Departamento de Letras Vernáculas da Universidade Estadual de Londrina (UEL). E-mail: sheilaol@uol.com.br ${ }^{66}$ Doutoranda em Estudos da Linguagem, pela Universidade Estadual de Londrina (UEL). Docente nos Anos Iniciais do Ensino Fundamental, pela Prefeitura Municipal de Londrina. Docente colaboradora no Departamento de Educação da Universidade Estadual de Londrina (UEL). E-mail: roalmeidaprofe@gmail.com 
professores de EJA a adaptar atividades retiradas dessas obras ou mesmo de páginas da internet, como esforço para atender à demanda dos estudantes pela leitura e escrita. Como o que se busca em tais publicações são as práticas relativas à apreensão da escrita, tais apropriações podem levar ao estudo apenas mecânico da escrita, ou até mesmo sob uma abordagem infantilizada, se a adaptação não for realizada de modo adequado.

Essas e outras problemáticas estão presentes no cotidiano do professor de EJA Fase I, de uma cidade média no interior do Paraná, onde está sendo realizado estudo de campo sobre leitura na EJA, como parte de pesquisa de tese relacionada ao tema.

Considerando-se a literatura como um direito humano, conforme postula Candido (1995), e a EJA como uma oportunidade de garantia de mais esse direito no processo de expansão do letramento que realiza, pretende-se neste trabalho apresentar algumas considerações teóricas que tomam a leitura como fenômeno complexo e que envolve, além do esforço sistemático e da cognição, elementos da subjetividade, instância nem sempre considerada na prática escolar. Nesse sentido chama-se a atenção para a necessidade de que a leitura literária venha a ser enfatizada dentre as experiências proporcionadas pela EJA.

Diante disso, embora haja inúmeros obstáculos a superar, a mediação de leitura é posta como um caminho possível a ser incorporado pelos docentes de EJA, visando à troca de interpretações, como ponte para a ampliação de conhecimentos. Busca-se, nesse sentido, uma forma de ensino mais contextualizada, na qual o acesso à leitura e à literatura estará realmente garantido, tendo em vista que não basta o contato com as obras, é preciso mediação para que os livros se tornem objetos de valor dentro das possíveis comunidades de leitores a serem criadas entre os estudantes.

Nesse contexto, entende-se que a "mediação de leitura" seja a possibilidade de se ter acesso a materiais de leitura e, mais que isso, a um mediador que possa considerar em suas práticas tanto elementos relacionados à aprendizagem e ao aprimoramento da leitura e da escrita, quanto à emancipação que esse saber pode gerar, se relacionado a obras de literatura, ampliando as possibilidades de fruição e de criticidade do indivíduo.

Iniciativas de acesso à literatura foram empreendidas pelo Ministério da Educação em edições anteriores dos Programas do Livro, como o Programa Nacional de Bibliotecas Escolares (PNBE), que nos anos de 2012 e 2014 disponibilizou obras literárias específicas para a EJA (BRASIL, 2014), tendo sido interrompido no ano de 2017, com a assimilação do programa pelo PNLD, nos editais de PNLD Literário.

Como o escopo desta pesquisa são as possibilidades de leitura literária na EJA, utilizase como metodologia, aliada à pesquisa bibliográfica, o estudo em campo, por meio de observações, entrevistas e práticas de mediação de leitura, que têm ocorrido em uma escola de porte médio, escolhida por nela conter parte dos referidos acervos, preservados separadamente dos contidos na biblioteca.

Enfatiza-se a necessidade da continuidade de iniciativas de acesso dos estudantes de EJA a acervos literários, defendendo-se ações que, além de distribuírem os livros, possam estar interligadas à formação de mediadores para práticas de leitura literárias com os estudantes de EJA.

\section{Leitura na EJA e subjetividade do leitor}

Pressupondo que a leitura não é um ato natural do ser humano, necessitando ser ensinada, em especial na escola, e que a leitura do texto escrito pode ampliar os conhecimentos e dar margem à imaginação do leitor, busca-se relatar práticas de mediação de leitura literária na Educação de Jovens e Adultos (EJA), que, além de motivarem à aprendizagem do sistema de escrita, permitem a expansão das condições de letramento, uma vez que favorecem o acesso a bens culturais que não estão totalmente disponíveis aos 
indivíduos não alfabetizados. Ademais, o contato mais profícuo com o texto literário pode favorecer uma relação com a leitura que esteja marcada pelo comparecimento da subjetividade, na medida em que fazem parte de sua constituição os intervalos a serem ocupados pelo leitor, a partir de suas experiências de mundo.

Nessa perspectiva, considerando a subjetividade como fator inerente ao processo de leitura, o filósofo e crítico literário francês Roland Barthes (2004) caracteriza a apropriação individual do texto como uma reescrita realizada pelo leitor, envolvendo todas as linguagens que atravessam os discursos e que formam a profundeza das frases, excedendo memória e consciência, imprimindo-se certa postura aos enunciados. Por meio desse processo, realiza-se uma relação regulada do texto sobre o indivíduo, de modo que a imaginação do leitor se soma à matéria palpável do escrito.

A antropóloga francesa Michèle Petit (2009), corroborando as ideias de Barthes quanto à subjetividade inerente ao processo de interação com o texto escrito, defende que, na leitura, a identidade dos próprios leitores entra em jogo, de modo que a experiência de ler pode estar relacionada a diferentes desejos, realizações e alternativas. Como resultado de suas pesquisas com jovens franceses, amparadas por essa perspectiva, ela conclui que a leitura pode definir transformações reais ou simbólicas em diferentes campos da vida, criando certo movimento no "tabuleiro social", podendo levar alguns jovens a serem mais autônomos e protagonistas de suas experiências.

Com base nas considerações de Petit (2009), a leitura pode levar à ampliação de informações, ao aprimoramento linguístico, à ampliação de horizontes e à aceitação da diversidade, entre outras possibilidades. Por conseguinte, infere-se que a leitura, em sua instância subjetiva, transforma a própria condição do indivíduo frente à realidade, ao influenciar sua maneira de ver os fatos, somando-se a isso um fator de imaginação ou mesmo de esperança, essencial à sobrevivência diante de certas adversidades.

Dessa forma, considerando-se que as trocas simbólicas entre leitor e texto precisam ser contempladas no ensino escolar, corroboram-se as ideias de Sheila Oliveira Lima (2016, p. 18), quanto à leitura como fenômeno complexo, que passa por diversas instâncias do corpo, em suas múltiplas compleições, resultando de processos que se iniciam no sistema neurofisiológico, até atingir um limite mais alto de abstração, envolvendo prazer, psiquismo e afetos. No caso da leitura em voz alta, segundo a fonoaudióloga brasileira Lucila Maria Pastorello (2015), há um resgate da corporeidade que foi recalcada pela escrita. Dessa forma, atribui-se à oralidade uma evidência corporal da interação ocorrida durante a atividade leitora.

Quando se trata do prazer que a leitura pode proporcionar, a literatura ganha destaque por constituir-se como instância cultural, em que estão envolvidos, entre outros fatores, arte e linguagem. Desse modo, como aponta María Teresa Andruetto (2017), por meio da leitura de literatura, são motivadas revoluções pessoais para a superação de dificuldades relacionadas ao texto escrito, assim, gradativamente, os sujeitos vivenciam, autonomamente, o prazer proporcionado por esse tipo de leitura.

Vale ressaltar que o leitor exerce papel ativo na leitura, de modo a relacionar seus conhecimentos de mundo ao texto que lhe é apresentado. Assim, evidencia-se que os fatores envolvidos na leitura não são apenas os cognitivos, havendo algo mais a ser explorado e que a maioria das práticas escolares têm ignorado, fatores da ordem do inconsciente e do desejo (LIMA, 2016).

Toda leitura constitui-se, ainda, como um processo em que comparece a intersubjetividade, no sentido das trocas afetivas. Assim, cada leitura é algo único, e cada leitor tem possibilidades de interpretar o texto à sua maneira, e expressar impressões de leitura. Nesse sentido, não há uma interpretação correta, mas muitas possíveis. A troca de interpretações seria, dessa forma, uma interessante forma de ampliação de leituras, em processos de construção coletiva de sentidos. 
Corroborando com essas ideias, a filóloga espanhola Tereza Colomer (2007) discorre sobre a importância da mediação e do compartilhamento de leitura como maneira de construir sentidos no coletivo que motivem ao movimento individual pelo esforço de ler, ampliando horizontes, de acordo com os desejos e a relação de cada leitor com os textos.

A corporeidade experimentada na leitura em voz alta, por sua vez, a ser evidenciada primeiramente pelo professor mediador em suas leituras para os alunos, pode ainda facilitar a apropriação da linguagem escrita como instrumento de práticas sociais e de práticas subjetivas. Se motivados constantemente, os alunos poderiam sentir-se instados a expressar também suas leituras em voz alta, ou mesmo suas impressões, gerando compartilhamentos de interpretações, e assim se criaria um ambiente em que a leitura realmente fosse um valor para o grupo de estudantes, ainda que estejam em fase de aquisição e aprimoramento quanto à leitura e à escrita, como ocorre na fase inicial da EJA.

Infere-se que, nas formas de ensino em que prevaleça o caráter subjetivo perante a leitura, esteja contemplada uma formação do leitor que leve os estudantes a complementar o texto com seus conhecimentos e impressões sobre o mundo e sobre si mesmos, possam trocar impressões e informações com outros leitores, integrando-se a grupos ou a comunidades de leitores, expandindo as relações humanas a partir do ato de ler.

\section{Experiências de leitura na EJA: desafios e possibilidades}

Como parte do acervo entregue pelo Ministério da Educação a escolas de EJA em 2014, no âmbito do último PNBE EJA, o Guia PNBE EJA 2014 (BRASIL, 2014), traz sugestões de trabalho literário, propostas por especialistas em leitura, contemplando livros de poemas, de prosa literária e de imagens.

Nesse contexto, as duas primeiras experiências aqui retratadas, desenvolvidas no ano de 2018, foram embasadas em livros de imagens contemplados no guia PNBE. Já na terceira, buscou-se uma gradação entre a presença das imagens e a introdução do texto verbal. Quanto à temática, no entanto, os livros, embora abordem assuntos diversos, como seca, relações amorosas e lembranças, todos têm relação com a memória dos estudantes jovens e adultos, por tratarem de temas universais, que fizeram ou fazem parte de suas vivências cotidianas. Essa proximidade pode gerar condições que motivem à aprendizagem da leitura e da escrita, e ao emprego dessas habilidades em experiências que se realizam além dos muros da escola, em especial em práticas subjetivas, como a possibilidade de ler para sentir prazer diante das obras de arte que os livros, os poemas, as narrativas, as imagens, constituem.

Como os estudantes da Fase I da EJA apresentam grandes dificuldades quanto à leitura e a escrita, até mesmo na codificação e na decodificação, decidiu-se por iniciar as práticas de leitura com livros de imagens, que pudessem acionar conhecimentos prévios dos estudantes e despertá-los para uma reflexão sobre a matéria literária presente em seus cotidianos por meio de músicas, imagens, textos orais e escritos. Desse modo, itens do Guia PNBE EJA 2014 foram considerados no planejamento das práticas, em especial o tópico Mediando a leitura de livros de imagem, em que há sugestões para o trabalho com as narrativas visuais, apontando entre as estratégias operacionais, a exploração individual, a discussão coletiva e o trabalho em pequenos grupos.

$\mathrm{Na}$ primeira prática de leitura com a Fase I da EJA, o livro $O$ voo da asa branca, de Rogério Soud, foi abordado no início de agosto de 2018, com a participação de seis estudantes - todas mulheres, na faixa dos 50 aos 70 anos -, a professora da $1^{\text {a }}$ etapa e o professor da $2^{\text {a }}$ etapa, ambos docentes da EJA Fase I.

Tal livro (SOUD, 2012), constitui-se como uma releitura da canção Asa branca, de Luiz Gonzaga e Humberto Teixeira, por meio somente de imagens. A obra apresenta 32 páginas, em formato 21,5 por $28 \mathrm{~cm}$, encadernado em brochura, tratando-se de sua primeira 
edição. As cenas retratam as vivências de um nordestino que sofre com a seca, até ao ponto de, em busca de uma vida melhor, abandonar sua terra, levando consigo a esperança de retornar para sua amada, que já espera um filho seu. O livro aborda o aspecto sequencial da narrativa e não o aspecto sonoro do poema. Suas imagens são repletas de metáforas e outros recursos artísticos que remetem à canção.

A referida prática realizou-se no espaço da biblioteca, mas não somente para a prática de leitura, pois os professores já haviam iniciado a aula naquele ambiente, para que não houvesse resistência dos estudantes em dirigir-se até lá para a prática com a pesquisadora, que, embora já estivesse realizando observações nas turmas, mediaria as práticas de leitura com eles pela primeira vez.

Antes de colocar a música para as estudantes, a pesquisadora questionou-as, preparando todas para possíveis comentários sobre o sertão do Brasil, sobre as cidades em que nasceram etc., o que as fez comentar sobre suas origens, e algumas lembranças, demostrando, ainda, a diversidade regional vivida na sala, de modo que havia duas participantes oriundas do Estado de Minas Gerais, uma da Bahia, e as outras de cidades do Paraná.

A partir do debate inicial, as alunas comentaram sobre como os antepassados vieram para a região de Londrina, expressando-se sobre as dificuldades que haviam enfrentado quando crianças. Durante a canção Asa branca, algumas participantes ficaram dançando na cadeira, outras cantaram, algumas conversaram, e, ao final, foram motivadas a falar sobre a letra da canção, a música ou os sentimentos suscitados a partir delas.

A maioria das estudantes considerou a letra como algo triste, por tratar da seca do Nordeste, abordar o amor e as dificuldades que os moradores de lá enfrentam. Uma senhora, no entanto, remeteu-se a uma lembrança positiva sobre seu pai, que tocava em bailes quando ela era criança, sendo que uma das músicas tocadas por ele era Asa branca.

Em seguida, a letra da canção foi lida em voz alta pela pesquisadora, e, no decorrer da leitura, as alunas faziam comentários sobre o Nordeste, sobre o calor "que lá é tanto que até há fumaça saindo do chão, como se estivesse dentro de uma fornalha". Disseram ainda que "é uma judiação ver os gados mortos, outros animais e as plantas secas". Ao se remeterem à ave asa-branca, referindo-se ao enunciado "até mesmo a asa branca/ bateu asas do sertão/ então eu disse adeus Rosinha/ guarda contigo meu coração", as alunas fizeram considerações a respeito dos processos de emigração, tanto na figura do pássaro quanto na do homem.

Após o compartilhamento das interpretações a partir da canção, a pesquisadora mostrou o livro $O$ voo da asa branca, para que as alunas realizassem uma primeira leitura exploratória das imagens que compõem a obra. A experiência foi muito positiva, pois houve uma riqueza de previsões sobre o texto, com algumas leitoras comentando a respeito dos elementos que constituem a narrativa: o capim seco, a terra rachada, a tristeza, o pássaro a que se referiram como a asa branca, mas que, a princípio, disseram ser uma garça, depois de um pombo. Também mencionaram o olhar triste do retirante, o que evidencia uma apreensão mais interpretativa do conteúdo veiculado pela obra.

Uma situação curiosa marcou a leitura de uma das alunas do grupo. Parecendo buscar uma história de caráter mais leve, fazia tentativas de previsão, parecendo esperar que a história fosse feliz, imaginando que, a cada cena, algo houvesse melhorado em relação à condição anterior. A partir dessa apreensão incomum da obra, seria possível inferir que as experiências da aluna com livros poderiam ter sido, até então, com obras elementares, que levam a esperar um final feliz. Entretanto, talvez a interpretação mais próxima do processo vivido pela aluna ao longo da leitura refira-se mais à apropriação subjetiva da obra, em que comparece o desejo por sensações agradáveis e deste modo ela busca "escrever sua leitura" (BARTHES, 2004). Corroborando com tal interpretação, ao término da leitura, a aluna opina sobre a necessidade de haver um outro livro que fosse $A$ volta da asa branca, chegando até a 
expressar algumas ideias para sua composição, num autêntico processo de escrita de sua leitura.

A partir dessa manifestação da aluna, pode-se refletir sobre a presença da subjetividade no processo de leitura, apontada por Barthes (2004), pois a apropriação individual do texto por parte dela gerou uma releitura, que veio a complementar, e até lançar ideias para uma resposta à obra, em uma perspectiva do sonho, do desejo de que a história fosse diferente, desprendida da dura realidade retratada. Talvez tais expectativas estejam relacionadas à memória de histórias ouvidas ou lidas e à consciência sobre outras possibilidades, mas é possível inferir também que há algo a mais que vincula a imaginação do leitor à escrita.

Houve também o caso de uma aluna, bastante religiosa, que, diante das imagens remeteu-se a Jesus como a personagem que sofria na história, em especial a partir das imagens que representavam o pé do retirante, as cenas em que aparecem sua sombra projetada em forma de cruz, e também ao ver a imagem de um pombo, que a levou a remetê-la a um anjo. Dessa forma, foi possível observar que a experiência da leitura conduziu ao reconhecimento de possíveis intertextualidades, mesmo não havendo por parte da aluna uma familiaridade com a literatura ou com a leitura.

Em meio aos comentários, uma aluna permaneceu com os olhos lacrimejando e, questionada sobre o motivo, revelou sua emoção ao constatar que a personagem do retirante deixa a mulher grávida para trás, identificando, ainda, a tristeza que envolve a situação da seca. Vale ressaltar que, ao longo da aula, várias vezes, ela repetia baixinho, "a seca é triste", como quem inscreve, na oralidade, um bordão, um refrão, uma síntese da própria leitura.

As expressões das personagens tocaram bastante as alunas de EJA, e no decorrer da leitura das imagens, houve comentários como: "já morei numa casinha assim também só com folhas de coqueiro tampando"; "onde tem um açude, aí o açude seca e fica a terra toda rachada daquela forma".

Ao término dos comentários, várias estudantes quiseram permanecer com o livro para lê-lo novamente. Diante da boa recepção que tiveram com a temática e com o livro, ao final, admirando o envolvimento delas em rever a história narrada por meio de imagens, a pesquisadora questionou "será que quem não sabe ler e escrever também pode ler esse livro?". As alunas responderam positivamente, afirmando ser possível entender o texto e reiterando, ainda, que não se tratava de livro infantil, pois uma criança não entenderia o sofrimento retratado na história, visto não ter experiência de vida para compreender a situação ali expressa.

A participação das estudantes revelou possibilidades para a leitura que vão além da apreensão do código, pois, a partir da motivação realizada nessa prática inicial, demonstraram que, para elas, os livros podem ser tomados como arte, e podem favorecer interessantes leituras, mesmo que ainda não tenham se apropriado do processo de decodificação da escrita.

Ao serem questionadas se haviam gostado de ter aula na biblioteca da escola, uma das estudantes revelou não gostar de ir àquele ambiente, dizendo não se sentir bem ali. Diante disso, a pesquisadora enfatizou que o espaço da biblioteca também pertence à EJA, reiterando haver outros livros ali presentes que poderiam ser tão interessantes quanto o que havia sido lido em aula. A aluna ficou pensativa, mas não disse nada.

$\mathrm{Na}$ semana seguinte, considerando que a narrativa visual havia motivado o interesse dos estudantes, foi realizada a segunda prática de leitura na EJA, a partir do livro Quando Maria encontrou João, de Rui de Oliveira (2012), com a participação de 11 estudantes.

A obra se constitui de, além da capa e da contracapa, 36 páginas, em formato de brochura, 27,5 por 20,5 , tratando-se de sua primeira edição. A narrativa visual retrata dois protagonistas, que no início do livro são um menino e uma menina, brincando em um jardim. No decorrer da narrativa, são separados pela figura de uma mulher adulta, e os dois 
protagonistas são retratados seguindo suas vidas separadamente, encontrando-se novamente ao fim da história, em que há o enunciado "e foram felizes para além do sempre".

$\mathrm{Na}$ ocasião, a biblioteca estava ocupada por livros didáticos nas mesas, em decorrência da escolha de livros relacionada ao PNLD para os anos iniciais do Ensino Fundamental. Por conseguinte, a prática foi realizada na sala de aula, onde a pesquisadora propôs que fizessem um círculo com as carteiras, mas os estudantes preferiram ficar em seus lugares, com as carteiras dispostas em filas.

Durante a apresentação da obra, os estudantes foram comentando suas impressões. Perceberam, com auxílio da pesquisadora, o processo de amadurecimento da protagonista e a ruptura na relação entre as duas crianças presentes no início pela interferência de um adulto. Comentaram que havia fotos de momentos importantes na vida da protagonista, mas não interligaram os percursos das duas personagens (a menina e o menino vivendo paralelamente). Somente ao final, fizeram estabeleceram essa relação, inferindo que se reencontraram para ficar juntos "além do sempre", como o texto verbal presente na última cena do livro indicava.

Ao final da leitura do livro de imagens, os estudantes permaneceram em silêncio e não demonstraram interesse em retomar a história. Diante dessa atitude, que se diferenciou daquela apresentada diante do livro lido na semana anterior, a pesquisadora recapitulou a história, fazendo comentários sobre possíveis interpretações, o que ampliou o interesse de alguns em folhear o livro por conta própria. Outros se mantiveram distanciados do livro.

A partir da relação evidenciada pelos estudantes entre conhecimentos de mundo e o texto imagético, infere-se uma aproximação com as considerações de Lima (2016), quanto à existência de outros fatores envolvidos na leitura, além dos cognitivos. Esses apontamentos são possíveis, porque, como a obra não foi apreciada pela maioria dos estudantes na ocasião, a pesquisadora, intrigada pela resistência de alguns à narrativa do livro, continuou questionando-os sobre o tema, o que parece ter motivado algumas estudantes viúvas a falar sobre as dificuldades que enfrentaram com seus companheiros na juventude. Assim, o tema do livro pareceu não agradar à turma por remeter a lembranças de momentos ruins que haviam vivenciado. É preciso, nesse sentido, considerar que também o silenciamento diante de uma obra pode significar uma leitura tão produtiva e profunda quanto aquelas que, como em $O$ voo da Asa Branca, expressam-se por meio de efusivas e numerosas falas por parte dos estudantes.

Como terceira obra abordada com os estudantes de EJA Fase I, o livro Caixinha de guardar o tempo, de Alessandra Roscoe (2012), ilustrado por Alexandre Rampazo, foi apresentado na quarta-feira, dia 29 de agosto, na biblioteca, onde os 14 estudantes presentes ficaram desde o início da aula deste dia.

A obra, que se refere à memória como um local onde se guardam lembranças, possui 32 páginas, em formato brochura, 20 por $20 \mathrm{~cm}$, com temática voltada à questão do tempo, da memória, das lembranças e valores pessoais, contendo texto verbal em forma de poema, e não-verbal, com imagens que remetem ao surrealismo.

Ao serem apresentados ao título da obra, os estudantes puderam antecipar impressões que ele gerava, falando sobre alguns significados que se podem atribuir ao termo "tempo". Alguns disseram que pensam na quantidade de tempo que se tem, ou não se tem, outros falaram da saudade, da infância, do passado. Uma aluna falou de futuro, outros ainda da vontade que têm de viver muito para terem tempo de ver seus tataranetos grandes. Também houve quem abordasse a correria cotidiana.

Durante a leitura da história, os estudantes faziam comentários, e chegaram a perceber que a caixinha de guardar lembranças era uma metáfora relacionada à memória. Uma das alunas, que se destaca por sua participação frequente, comentou sobre suas lembranças tristes, e disse que hoje se sente rica, porque, quando jovem, ficava em seu barraco de sapê, no alto, para não ser pega por "onça”. Disse também que sentia saudade das crianças que perdera. 
Outra estudante, que está em tratamento contra câncer, revelou que pensa em quanto tempo terá ainda de vida. Uma das passagens do livro trazia uma metáfora relacionada à "pescaria", o que levou as alunas a falarem sobre o sentido real do termo e relacioná-lo às suas lembranças. Citaram a alegria que têm em lembrar das tardes que passavam pescando com a família, assunto recorrente na fala de duas das estudantes.

A partir dessa última experiência, é possível confirmar a singularidade de cada leitor, de cada leitura e as muitas possibilidades de interpretação, e que a troca de interpretações é essencial na construção coletiva de sentidos. Nesse processo, é muito importante também a figura de um mediador, que venha a propiciar o compartilhamento, ação que motiva para o esforço de ler, como evidenciado diante da iniciativa da maioria dos estudantes em manipular, ler e revisitar os livros ao final das leituras coletivas. Considera-se, nesse sentido, que essas ações caracterizam um real acesso ao livro, encaminhamento válido para a superação de dificuldades iniciais relacionadas à leitura, em especial do texto literário, e, como postula Andruetto (2017), um movimento de descobertas sobre o mundo, e sobre si mesmos, explorando potenciais sobre os quais já estavam convencidos de não terem.

Mediante as práticas já realizadas com a Fase I da EJA, os principais desafios que se interpõem são relacionados ao interesse dos estudantes em participar de tais atividades, expondo opiniões e sensações, e quanto à concomitância entre a fruição propiciada pelas abordagens coletivas das histórias e a aprendizagem da leitura e da escrita. Desafios que se tem procurado superar a partir da exploração do sentido e da grafia de termos e expressões presentes nos livros literários.

Como principais desafios relativos à leitura na fase inicial de EJA, a falta de domínio da leitura e da escrita é elemento que gera insegurança à maioria dos estudantes, fazendo da biblioteca um ambiente no qual não se sentem à vontade, como é o caso de uma das alunas, que declarou isso com ênfase na primeira prática, mas tem se aberto às possibilidades no decorrer das experiências. Na mesma direção, o livro que traz o texto verbal como linguagem primordial mostrou-se como algo que tende a inibir os alunos diante da leitura, levando-os à preferência por livros de imagens, por exemplo.

Diante desses desafios, despontam possibilidades para a leitura literária na EJA, como a relação entre músicas e livros de imagens, a passagem gradativa da leitura de imagens para a leitura de pequenos textos com enunciados verbais, a relação entre temáticas presentes nos livros e as vivências dos educandos. Tudo isso leva à inferência de que, mesmo sem o domínio completo da leitura e da escrita, esse tipo de texto pode ser experienciado e apreciado pelos estudantes, por meio da mediação, e da gradativa superação de bloqueios que os afastam do prazer perante a literatura, levando-os a percebê-la como arte humana que atende aos interesses subjetivos, elemento afetivo que pode despertar para a aprendizagem efetiva da leitura e da escrita.

\section{Considerações finais}

O trabalho com a leitura na EJA é permeado por desafios que envolvem o acesso a materiais didáticos, a visão mecânica que muitos têm em relação ao ensino de leitura, as dificuldades dos estudantes quanto à apropriação da escrita, entre outros. No entanto, considerando que em algumas escolas do segmento há livros de literatura, disponibilizados pelo extinto PNBE EJA, este estudo pautou-se pela investigação quanto às possibilidades de leitura literária por parte dos estudantes, atendendo ao direito de acesso de qualidade que têm em relação também a esse tipo de texto.

Assim, retrataram-se práticas de leitura com a EJA envolvendo três obras, dentre os cinquenta livros presentes nos acervos PNBE EJA 2014. Constatou-se, já a partir dessas práticas, que a subjetividade leitora permeia as interpretações dos estudantes, levando-os a um 
movimento de relação entre suas vivências e as considerações expressas nos textos, de modo a se motivarem à leitura individual.

Nessa conjuntura, constata-se que os caminhos à formação do leitor dependem também do compromisso escolar de assumir a leitura literária como conteúdo essencial, propiciando aos professores atuarem como mediadores, propulsores do acesso real à matéria que os livros podem veicular. Frente a essa evidência, restam desafios múltiplos a serem superados e se amplia o espaço para pesquisas sobre as práticas subjetivas e intersubjetivas de leitura com estudantes da EJA.

\section{Referências}

ANDRUETTO, M. T. A leitura, outra revolução. Tradução de Newton Cunha. São Paulo: Edições Sesc São Paulo, 2017.

BARTHES, R. O rumor da língua. Tradução de Mario Laranjeira. São Paulo: Martins Fontes, 2004.

BRASIL. PNBE na escola: literatura fora da caixa. Elaborado pelo Centro de Alfabetização, Leitura e Escrita da Universidade Federal de Minas

Gerais. Brasília: Ministério da Educação, Secretaria de Educação Básica, 2014. Disponível em:

$<$ http://portal.mec.gov.br/index.php?option=com_docman\&view $=$ download\&alias $=15610$ guia-eja-leituraforadacaixa-pdf\&category_slug=maio-2014-pdf\&Itemid $=30192>$. Acesso em: 11 out. 2017.

CANDIDO, A. O direito à Literatura. In: . Vários escritos. São Paulo: Duas Cidades, 1995. p. 169-191.

COLOMER, T. Andar entre livros: a leitura literária na escola. Tradução de Laura Sandroni. São Paulo: Global, 2007.

FREIRE, P. A importância do ato de ler: em três artigos que se completam. São Paulo: Autores Associados: Cortez, 1989.

LIMA, S. O. Subjetividade e formação do leitor: o problema da ausência da leitura literária em livros didáticos do ciclo 1 do ensino fundamental. In: Revista Terra Roxa e Outras Terras: v. 31, dez. Londrina-PR, 2016. P.18-30. Disponível em:

$<$ http://www.uel.br/revistas/uel/index.php/terraroxa/article/view/27154/20584>. Acesso em 8 ago. 2017.

OLIVEIRA, R. Quando Maria encontrou João. Rio de Janeiro: Nova Fronteira, 2012.

PASTORELLO, L. M. Leitura em voz alta e produção da subjetividade. In: Leitura em voz alta e produção da subjetividade: um caminho para a apropriação da escrita. São Paulo: Editora da Universidade de São Paulo, 2015. P. 55-76.

PETIT, M. Os jovens e a leitura: uma nova perspectiva. 2 ed. Tradução de Celina Olga de Souza. São Paulo: 34, 2009.

ROSCOE, A. Caixinha de guardar o tempo. Ilustrações de Alexandre Rampazzo. São Paulo: Gaivota, 2012.

SOUD, R. O voo da Asa Branca. São Paulo: Prumo, 2012.

Submetido em 26/09/18

Aceito em 10/12/2018 